\title{
EVALUATING LEARNERS'S ABILITY TO USE TECHNOLOGY IN DISTANCE EDUCATION: THE CASE OF EXTERNAL DEGREE PROGRAMME OF THE UNIVERSITY OF NAIROBI
}

\author{
Ouma OMITO \\ Department of Curriculum Instruction and Media \\ Rongo University, Kenya
}

\section{ABSRACT}

The study was aimed at investigating the students' ability to use technology for distance education with specific reference to the University of Nairobi's External Degree Program. To achieve this, one specific objective was formulated: To find out the student teacher's readiness to accept and utilize technology for learning purposes in relation to their work experience. The study design used was cross- sectional survey with a well -constructed questionnaire. The study population was 500 External Degree Students of the University of Nairobi who were final year students in the Bachelor of Education (Arts) by distance mode. The study sample of $\mathbf{2 1 7}$ was reached at by the use of a sample table provided by Krejcie and Morgan, (1970). Simple random sampling technique was used to identify the 217 respondents. A total of $\mathbf{1 1 0}$ questionnaires were filled and returned by respondents who were mainly primary school teachers in Kenya. A non-probability sampling technique (purposive) was used to select the cohort under study, that is, the final semester students in the External Degree Program of the University of Nairobi. The results from the pilot study were used to prove content validity as instrument reliability was determined from the internal consistency of responses from the questionnaires after the pilot study. The findings from the study revealed that majority of teachers $19(50 \%)$ who had a work experience between 6 to 11 years were able to gather information from the internet for learning purposes. It was also learnt that as the number of years of work experience increased (21 years and above), the ability to gather information from the internet decreased drastically. When respondents were asked of their ability to troubleshoot computers, all categories of work experience showed low ability. All percentages were less than $50 \%$ with the work experience brackets of 21 and above years which recorded $22.2 \%$, emerged as the highest percentage. Finally, when respondents were asked about their feelings towards using computers for their additional research and education, the work experience brackets of 21 and above years overwhelmingly, $6(67.7 \%)$, enjoyed working with computers. It was, therefore, concluded that any institution aiming at introducing e-learning in their institution should assess students' technology literacy levels and prepare them in advance before the launch of e-learning.

Keywords: e-Learning, Wedusoft, distance learning, distance education, e-learning uptake, information literacy.

\section{INTRODUCTION}

Education is seen as the indispensable agent to bring about the change between what we are and what we want to be. In this context the role of distance education, as part of the mainstream education, is not an option but an unavoidable imperative for many students all over the world. Distance education (DE) provides access to higher education and especially to the growing student population of traditional and non-traditional students, (Reddy and Manjulika, 2002), who may be subject to constraints such as time, distance or a physical disability etc and, therefore, are not able to attend traditional courses on campus. The higher learning institutions needs to take into account the high demands and the 
central role that education play in our society, that is, internationally, regionally and nationally.

Distance education is a technology driven education. It is the separation of the teacher and the learner in time and space. However, in synchronous distance learning, the element of time does not arise. Technology bridges the gap of time since learning takes place in real time (Keegan, 1996). In both synchronous and asynchronous learning environment, technology is central in distance education. One area that should therefore not be ignored in distance education is the student's ability to engage with technology for learning purposes. Distance education allows for the modelling of the effective use of technology in learning, an important skill for faculty involved in education (International Society for Technology in Education, 2002; National Council for Accreditation of Teacher Education, 2006).This is supported by the convergence of powerful computers with telecommunication technologies over the past three decades that has precipitated the fundamental shift in human history (Reddy and Manjulika, 2002).

Universities have begun to promote distance learning processes and make use of Information and Communication Technologies (ICTs) so as to offer their learners away to develop new competencies as well as to take advantage of flexibility of time and space. The use of distance learning tools is expanding in the field of education and this has led to more and more institutions offering distance learning curriculums through various distance learning practices and models such as e-learning platforms, school based programs and open educational resources (Armando, 2014). It is believed that there is an unstoppable paradigm shift in the design, development and delivery of education in higher institutions of learning. In addition, distance education has drastically increased the opportunities for the underserved populations. This is witnessed by the fairly recent proliferation and success of on-line universities, and its happenings in spite of criticism of e-learning and online degree programs among the popular press (Milligan and Buckenmeyer, 2008). In addition, e-learning is a major trend, that is, the most rapidly growing segment of distance education.

University of Nairobi is no exception. It is the oldest university in Kenya and among the very many universities in the world that offers distance education. There is an evidence that this university is involved in the recruitment and training of school teachers by distance learning mode as shown in the table below.

Table: 1 Enrolment of Students in the B.Ed. (Arts) by Distance Learning, UON 2001-2006

\begin{tabular}{lll}
\hline Academic Year & Month & Student Enrolment \\
\hline 2001 & April Intake & 600 \\
& December Intake & 737 \\
2002 & April Intake & 994 \\
2003 & December Intake & 1025 \\
2004 & April Intake & 1550 \\
& December Intake & 1420 \\
2005 & August Intake & 682 \\
2006 & April Intake & 353 \\
\hline
\end{tabular}

Source: Wanjala and Otigo (2010)

To further show the university's commitment to e-learning, the University of Nairobi owned an e-learning platform (Wedusoft) and engaged in training students and lecturers on its use as shown in the table below. 
Table: 2

Training of University of Nairobi students

\begin{tabular}{llc}
\hline Year & Course & Number of Students \\
\hline 2005 & Diploma & 17 \\
2006 & Diploma & 60 \\
2006 & Master & 20 \\
2007 & Master & 40 \\
\hline
\end{tabular}

Source: ICT Centre, University of Nairobi (2009).

Bachelor of Education (Arts) by distance studies which forms the scope of this research was tailored to cater for the many Kenyan students with minimum university entry requirements but who could not get the limited and competitive chances in the Kenyan public universities. Teaching and learning in this program was done in two phases; face to face done on-campus which catered for only $33.3 \%$ (15 hours) and self-study done offcampus that catered for $67.7 \%$ (30 hours) of the required course contact hours. Print media designed inform of course modules was the main source of content. Online delivery requires training and sensitization of both staff and students to engage in mutual exchange but the scenario at the University of Nairobi was that many students of the External Degree Programme had not been trained to use the e-learning platform and the very few who used computers either did so to type their term papers or accessing general learning materials in the internet.

\section{STATEMENT OF THE PROBLEM}

The presence of distance learning students and the online training of students as shown in both table 1 and 2 under background to the study validated the University of Nairobi's commitment to offering e-learning to students and more particularly to school teachers who were in this case distance learners. Driven by the above concern, this study attempted to answer the following research question in order to maximize the utilization of the benefits of University of Nairobi's e-learning platform: Are the Bachelor of Education (Arts) students of the University of Nairobi who are taking their studies by distance learning mode adequately prepared to adopt, sustain and use technology for their learning purposes?

The main objective of this study was to find out the student teacher's readiness to accept and utilize technology for learning purposes in relation to their work experience.

\section{LITERATURE REVIEW}

Information literacy in this research refers to the ability to seek information using a variety of effective computer search strategies (Anastasi and Cochrane, 2006). In a research conducted at University College Dublin comparing final year biochemistry students' and first year biology students, it was found that $27 \%$ of the first year biology students and $56.5 \%$ of final year biochemistry students were under-educated in the information seeking technology and processes (Callinan, 2005). In another similar study in the United Kingdom, it was found that higher education students made insufficient use of electronic learning systems in overall (Rowley, Banwell, Gannon-Leary, Urquhart and Armstrong, 2002). The same study also observed that non-traditional students in higher education generally had lower levels of information literacy and required extensive tutorial assistance by e-learning staff in the initial stages of their study program. This might have also been a similar case with Bachelor of Education (Arts) students of the University of Nairobi. 
Literature also revealed that self-efficacy; personality and study approaches have significant impact on information searching behavior by students (Anastasi and Cochrane, 2006). Kurbanoglu (2003) conducted a study on information literacy levels among the students enrolled in an Information Management Course throughout their study program. It was found that the program of study did not provide students with enough opportunity to practice newly acquired information seeking skills in order to develop a sense of selfefficacy with both, the process and the e-learning facility itself.

Many African academicians and students still lacked capacity as far as e-learning skills were concerned. Since that was the case, e-learning platforms and many other products were not fully utilized by faculty members in many African institutions. As a result of that inadequacy, a significant fraction of academicians had a negative attitude towards elearning as a mode of delivery for higher education. They did not believe that quality education could be delivered through information technology (Juma, 2001). One reason for such a negative attitude was technophobia. Technophobia sees technology as the solution to all human problems (Britain and Liber, 1999).

"The technophobes are most likely those who did not grow using computer...their personal aversion and anxiety about computers may be due to many reasons. They may like what they are used to doing and do not wish to change. They may feel experienced.... They may not want their awkward efforts to learn the new technology....subjected to public scrutiny. They may feel that it is too late in their lives to learn something completely new and different....they may be afraid of breaking a complicated and expensive piece of equipment (Soong, 2002)."

Independent variable

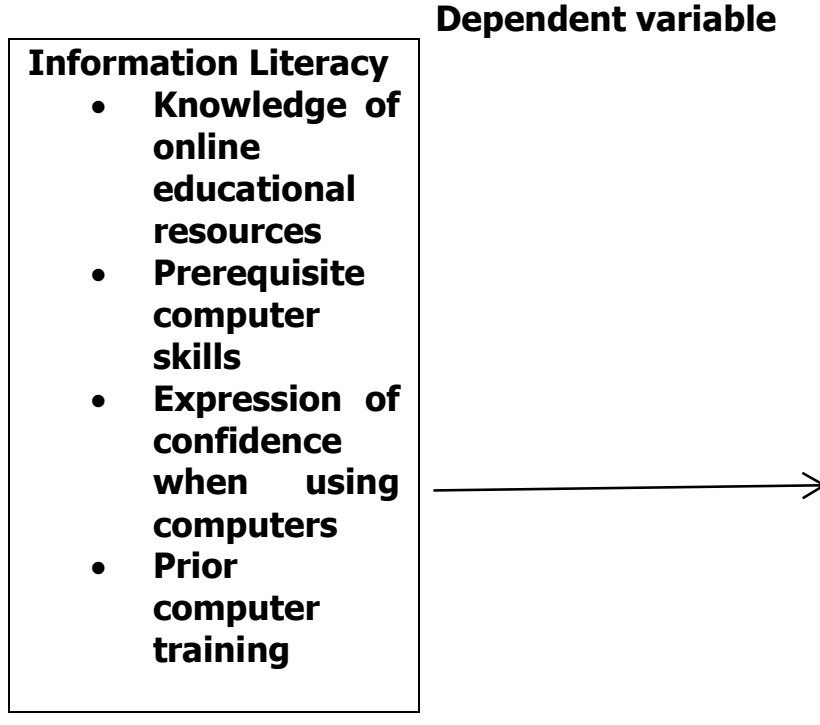

Uptake of e-learning

- Typing class assignments

- Online research

- Possessing and using of a computer

- Use of emails etc.

- Visiting cyber cafes

Source: Research data

Figure 1: Conceptual Framework 


\section{METHODOLOGY}

\section{Research Design}

The design used in this study was a case study. Cross sectional survey was used. According to Tolmie, Muijs, and McAteer (2011 p.36), cross-sectional survey design is carried out at one point in time by individuals within selected group or cross-sections of the target population. Survey is also said to be an attempt to collect data from members of a population in order to determine the current status of that population with respect to one or more variables (Mugenda and Mugenda, 2003). The survey design is suitable because it is characterized by a systematic collection of data from members of a given population. Survey design was also appropriate because for this study because it described and reported the preparedness level of students under study with a higher degree of accuracy. This is because survey design is a systematic empirical enquiry in which the researcher does not have control over the independent variables because their manifestations have already occurred or simply they are inherently manipulate able. Oketch (2013) in her unpublished masters project at the University of Nairobi also observed that cross-sectional survey can successfully be used in social sciences to gather the required data for the research since it allows researchers to look at numerous variables such as age, education level, gender etc at once, takes place at a single point in time (Tolmie, Muijs and McAteer, 2011) and often used to look at the prevalence of something in a given population. Cross sectional survey in the context of this study can measure e-learning uptake in terms of institutional needs of educational services as they relate to program (Creswell, 2012 p.378). As such, inferences about relationship among variables were made without direct intervention from variation of independent and dependent variables. The final part of the Bachelor of Education (Arts) of the University of Nairobi was therefore seen as a cross section and a representative of the External Degree Program of the University of Nairobi.

\section{Target Population}

Borg and Gall (1998), defined target population as all the number of real or hypothetical set of people, events of objects to which a researcher generalizes the results of the research study. According to Luck and Rubin (1993) as cited by Anyona (2009), two categories of respondents are necessary in research, and these are the informed specialists and the consumers or users. Based on such facts, the consumers of distance learning program for this particular research were the final year external degree students taking Bachelor of Education (Arts) by distance learning at the College of Education and External Studies of the University of Nairobi.

\section{Sample Size and Sampling Procedure}

This section describes the procedure used in sampling and gives the sample size for the final group of Bachelor of Education (Arts) students from the External Degree Program of the University of Nairobi. To determine the sample size, both probability and nonprobability sampling techniques were used. Non probability sampling was used to pick part 6 from the rest of the parts $(1,2,3,4$ and 5) making up the External Degree Program of the University of Nairobi. For an appropriate sample size of distance learners, a table provided by Krejcie and Morgan (1970) was used. The table gives the required the sample size for various population sizes. The total number of students for this (part 6) cohort was 500.This was inclusive of drop out cases. According to the table provided by Krejcie and Morgan (1970), the sample size for this study was 217 students. Since the population was not homogeneous, the researcher used simple random sampling. This involved random selection of the respondents provided they were members of the group under study (Weirsma, 1969). 
Table: 3

Study population

\begin{tabular}{llll}
\hline Target Population & Study population & Sampled Size & Percentage \\
$\begin{array}{l}\text { Distance learning } \\
\text { students }\end{array}$ & 500 & $\mathbf{2 1 7}$ & 43.3 \\
\hline
\end{tabular}

\section{RESEARCH INSTRUMENTS}

Since the research design is survey, the researcher used a questionnaire. A questionnaire is a data gathering instrument used when factual information is desired (Best and Khan, 2003). It was important for this study because the researcher administering the instrument had an opportunity to establish rapport, explain the purpose under study, and as well explain the meanings of items that were not clear. The researcher used a closed questionnaire for this research. The researcher administered questionnaires to 217 distance learning students. The questions asked were centered more on their feelings of students on their comfort with the use of technology especially computers for learning.

\section{Instrument Validity}

According to Weirsma (1969), validity refers to the extent to which the instrument reflects the behaviour under study. It involves a systematic investigation of the instrument's items to determine whether or not they make up a representative sample of behavioral dimensions or traits to be measured. Content validity is a measure of degree to which data collected using a particular instrument represents a specific domain of indicators or content of a specific concept (Mugenda and Mugenda, 1999).The content validity was picked for use in this study as it was based on the results and comments of the pilot study.

\section{Instrument Reliability}

Reliability of the instrument is the degree of consistency that the instrument demonstrates (Best, 1998:276). Weirsma (1966) says reliability means consistency of the measuring instrument. Rose and Stanley (1954), refer to reliability as the degree to which an instrument agrees with itself. An instrument is reliable when it can measure the variables accurately and consistently and obtain the same results under the same conditions over a period of time. According to Njagi (2013) in his PhD theses, a test must be valid in order for it to be reliable. For this research, a pilot study was conducted on some External B.Ed (Arts) students from other cohorts which were not under the study with the aim of indicating reliability on the questionnaire. The internal consistency of data was determined from scores obtained from single test that the researcher administered to indicate whether the questionnaires were reliable tools for this research.

\section{Data Collection Procedures}

The administration of research data collection instrument was done by the researcher both at the pilot and main study. The main research instrument used for data collection was a questionnaire administered to students during their residential sessions. Upon the approval of the research instruments, the researcher obtained a research permit from the Ministry of Education, Science and Technology. The collected data were grouped and coded for data analysis.

\section{Data Analysis Techniques}

The researcher used a number of statistical methods to analyze the collected data. These included quantitative techniques. The data was analyzed by each question asked. The researcher used frequencies, tables, percentages, mean score and total scores. 


\section{Ethical Considerations}

A research permit was obtained from the Ministry of Science and Technology. A copy of this permit was presented to the Dean, School of Continuing and Distance Education, University of Nairobi. All respondents were assured of confidentiality and security. Ethical issues were considered in all components of this research. Efforts were made to ensure there was no academic theft in this research. All sourced data and information were properly cited and referenced.

\section{DATA ANALYSIS AND INTERPRETATION OF FINDINGS}

\section{Research Question 1: Can You Use the Internet to Gather Data?}

Table: 4

Distribution of B.Ed (arts) students by work experience on their ability to use the internet to gather data

\begin{tabular}{lllll}
\hline Work experience & Sample size & Response & Frequency & Percent \\
\hline Below one year & 0 & Yes & 0 & 0.0 \\
& & No & 0 & 0.0 \\
$1-5$ & 6 & Yes & 2 & 33.3 \\
& & No & 4 & 66.7 \\
$6-11$ & \multirow{2}{*}{38} & Yes & 19 & 50.0 \\
& & No & 19 & 50.0 \\
$11-20$ & 57 & Yes & 10 & 17.5 \\
& & No & 47 & 82.5 \\
$21+$ & 9 & Yes & 2 & 22.2 \\
& & No & 7 & 77.8 \\
Total & 110 & & 110 & \\
\hline
\end{tabular}

From the above table, no student was reported to have a work experience of less than one year. 6 students were reported to have worked for a period between 1 and 6 years. 2 $(33.3 \%)$ students could use the internet to gather data. $4(66.7 \%)$ students could not use the internet to gather data. 38 students had their work experience periods ranging from 6 to 10 years. Out of this, $19(50.0 \%)$ students could use the internet to gather data. Another $19(50.0 \%)$ students could also not use the internet to gather data. 57 students were within the work experience brackets of 11 and 20 years. It was observed that 10 (17.5\%) students could use the internet to gather data. $47(82.5 \%)$ students could not use the internet to gather data. 9 students were found to have worked for over 21 years. 2 (22.2\%) students from this category could use the internet to gather data. $7(77.8 \%)$ students could not gather the data using the internet. 
Table: 5

B.Ed (Arts) students' distribution by work experience on their ability to troubleshoot internet problems

\begin{tabular}{lllll}
\hline Work experience & Sample size & Response & Frequency & Percent \\
\hline Below one year & 0 & Yes & 0 & 0.0 \\
& & No & 0 & 0.0 \\
$1-5$ & \multirow{2}{*}{6} & Yes & 1 & 16.7 \\
& & No & 5 & 83.3 \\
$6-11$ & \multirow{2}{*}{38} & Yes & 7 & 18.4 \\
& & No & 31 & 81.6 \\
$11-20$ & 57 & Yes & 2 & 3.5 \\
& & No & 55 & 96.5 \\
$21+$ & 9 & Yes & 2 & 22.2 \\
& & No & 7 & 77.8 \\
Total & 110 & & 110 & \\
\hline
\end{tabular}

From the above table, no student had a work experience below one year. 6 students had a work experience period between 1 and 5 years. Only $1(16.7 \%)$ student could troubleshoot the internet problems. $5(83.3 \%)$ students could not troubleshoot internet problems.

38 students were reported to have a work experience period between 6 and 10 years. 7 $(18.4 \%)$ students could troubleshoot internet problems. $31(81.6 \%)$ students could not troubleshoot internet problems.

57 students had worked for a period between 11 and 20 years. $2(3.5 \%)$ students could troubleshoot internet problems. $55(96.5 \%)$ students could not troubleshoot internet problems. 9 students had worked for over 21 years. 2 (22.2\%) students could troubleshoot the internet problems. $7(77.8 \%)$ students could not troubleshoot internet problem. 
Table: 6

B.Ed (Arts) students' responses by work experience on their ability to work with computers easily

\begin{tabular}{ccccc}
\hline Work experience & Sample size & Response & Frequency & Percent \\
\hline Below one year & 0 & Yes & 0 & 0.0 \\
$15-5$ & & No & 0 & 0.0 \\
& 6 & Yes & 2 & 33.3 \\
$6-11$ & & No & 4 & 66.7 \\
& 38 & Yes & 24 & 63.2 \\
$11-20$ & & No & 14 & 36.2 \\
& 57 & Yes & 18 & 31.6 \\
$21+$ & & No & 39 & 68.4 \\
& 9 & Yes & 6 & 66.7 \\
Total & & No & 3 & 33.3 \\
\hline
\end{tabular}

In the above table, no student had worked for a period less than one year. 6 students had worked for a period between 1 and 5 years. 2 (33.3\%) found working with computers easy. $4(66.7 \%)$ found working with computers difficult. 38 students had a work experience period between 6 and 10 years. $24(63.2 \%)$ students found working with computers easy. $14(36.8 \%)$ students found working with computers difficult.

57 students had worked for a period between 11 and 20 years. 18 (31.6\%) students found it easy to work with computers. $39(68.4 \%)$ could not find it easy to work with computers. 9 students had worked for over 21 years. $6(66.7 \%)$ students could work with computers easily. $3(33.3 \%)$ students found working with computes to be difficult.

\section{CONCLUSION}

On the ability to gather information from the internet based on research question 1, majority of students lacked the skills to gather data from the internet hence no relationship was found between work experience and the students' ability to gather data from internet. It was also concluded that across the work experience, it was observed that majority of the students from all categories of work experience brackets could not troubleshoot internet problems. Hence, no relationship existed between work experience and ability to troubleshoot internet problems. Lastly, the research findings revealed that the majority of students with the working experience of over 21 years had a higher percentage $(66.7 \%)$ of ability to work with computers easily. This in essence meant that technology adoption was a new phenomenon in Kenya and was more embraced by the younger generation compared to older generation. Among the three areas of technology readiness, troubleshooting remained to be a major barrier for students who were working with computers. In short, before the adoption of any distance learning program in any institution of learning, a consideration of technological readiness of the students should be taken into account.

Author's Note: This is a part of improved Master Project. 


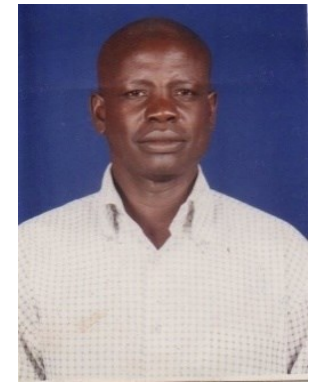

Ouma OMITO is a PhD student of Educational Communication and Technology at Rongo University College in Kenya. He is currently writing a PhD thesis entitled 'Readiness for the uptake of laptop computers in selected public primary schools in Homa Bay County, Kenya. He holds a distinction master degree in Distance Education from the University of Nairobi which he did on scholarship from the University of Nairobi. Currently he is serving as a school teacher and part-time lecturer of education at Rongo University College.

Mr. Ouma OMITO

P.O. Box 646-40300, Homa Bay, Kenya.

GSM: + 254722106659.

e-Mail: oumaomito@yahoo.com

\section{REFERENCES}

ACSA Literature Review. (2008). Putting Learning Back into E-learning. Survey of Good Practice in E-learning. Australia: Aged and Community Services.

Amando C. O. (2014). Predicting International Critical Success Factors in e-learning: A comparison of four universities from China, Mexico, Spain and USA. Doctoral Theses. University of Catalunya.

Anastasi, J. \& Cochrane S. (2006). Networked Learning. Australia: Central Queensland University.

Anyona, J. K. (2009). PhD Theses. The status and challenges of open and distance learning in kenya's public universities. Kenyatta University, Kenya.

Best, J. W \& Khan, V. J. (1998). Research in Education. Boston: Ally al Bacon.

Britain, S. \& Liber, O. (1999). A Framework for Pedagogical Evaluation of virtual learning environments. Bangor: University of Wales. http://www.leads.ac.uk

Borg, W. R \& Gall, M. D. (1998). Educational Research: An introduction, (4 ${ }^{\text {th }}$ ed.). NewYork: Longman Publishers.

Callinan, J. E (2005) Information-seeking behaviour of undergraduate biology students, LibraryReview, 54, 2,86-99.

Creswell, J. W. (2012). Educational Research. Planning, Conducting, Evaluating Qualitative and Quantitative Research, (4 ${ }^{\text {th }}$ ed.).University of Nebraska-Lincoln

Juma, M. (2001). The Establishment of a Higher Education Open and Distance Learning Knowledge Base for Decision Makers in Kenya, http://www.UNESCO.org/ education/studyingabroad/highlight/od/kb/kenya.doc

Keegan, D. (1996). Foundations of Distance Education. $3^{\text {rd }}$ Ed. New York: Routledge.

KIM, (2009). Fundamentals of Research Methods. KIM Management Training Series. Macmillan Kenya Publishers. Nairobi.

Kurbanoglu, S. S. (2003) Self-efficacy: a concept closely linked to information literacy and lifelong learning, Journal of Documentation, 59, 5, 35-646. 
Krejcie, V. R. \& Morgan, D. (1970). Determining Sample Size for Research Activities:Educational and Psychological Measurement. Vol. 30 No. 3 p.688.

Milligan, A. \& Buckenmeyer, J. (2008). Assessing Students for Online Learning. International Journal on E-Learning. 7 (3), pp. 449-461. Chesapeake, VA: AACE.

Mugenda, M. O. \& Mugenda, G. A. (2003). Research Methods, Quantitative and Qualitative Approaches. Nairobi: Acts Press.

National Centre for Education Statistics (1998). Internet Access in Public Schools. Washington, DC: US Department of Education.

Njagi , M. M. (2013). PhD Theses. Assessment of the Status of E-Learning as Course Delivery Method in Public Universities in Kenya. Kenya University, Kenya.

Oketch, H.A.(2013). Masters Project. E-learning readiness assessment model in Kenya's higher education institutions. University of Nairobi

Reddy, V. \& Manjulika, S. (2002). Towards Virtualization: Open and Distance Learning. Viriod Vasishtha India.

Rowley, J., Banwell, L., Childs, S., Gannon-Leary, P., Lonsdale, R., Urquhart, C \&Armstrong, C. (2002) User behaviour in relation to Electronic Information Services Within the UK Higher Education Academic Community, Journal of Educational Media, 27, 3, 107-122

Soong, R. (2002). Technophobia. http://www.zonalatina.com

Tolmie, A., Muijs, D. \& McAteer, E. (2011). Quantitative Methods in Educational and Social Research Using SPSS. Open University Press.

Wiersma, W. (1969). Research Methods in Education: An Introduction. University of Toledo, New York. 